Results The mean CsA dosage at 48 weeks was $2.8 \mathrm{mg} / \mathrm{kg} / \mathrm{day}$ in the CsA and placebo group and $3.0 \mathrm{mg} / \mathrm{kg} /$ day in the CsA and MTX group. After 48 weeks of treatment mean creatinine rose significantly $19 \mu \mathrm{mol} / \mathrm{L}(+25 \%)$ in the CsA and placebo group, and $21 \mu \mathrm{mol} / \mathrm{L}(+28 \%)$ in the CsA and MTX group ( $\mathrm{p}=0.28$ between groups). Changes in blood pressure and liver enzymes were not significant and clinically different between the two groups.

Table 1: premature discontinuations due to:

\begin{tabular}{lll}
\multicolumn{2}{l}{ Abstract FRI0031 Table 1} \\
\hline & $\begin{array}{l}\text { Renal toxicity and/or } \\
\text { hypertension }\end{array}$ & $\begin{array}{l}\text { Other kinds of } \\
\text { toxicity }\end{array}$ \\
\hline CSA + placebo $(n=60)$ & 2 & 4 \\
CSA + MTX $(n=60)$ & 9 & 3 \\
P-value (Fischer exact & 0.05 & 1.0 \\
tests) & & \\
\hline
\end{tabular}

Conclusion Therapy with CsA and MTX in early RA does on average not result in more clinically relevant renal or hepatic toxicity than CsA alone, but a trend towards more discontinuations due to renal toxicity and hypertension was observed

\section{FRI0032 INCIDENCE OF CLINICALLY RELEVANT INFECTIONS ASSOCIATED WITH RHEUMATOID ARTHRITIS (RA) THERAPIES}

${ }^{1} \mathrm{O}$ Gluck, ${ }^{1} \mathrm{~J}$ Tesser, ${ }^{2} \mathrm{G}$ Lawless, ${ }^{3} \mathrm{SW}$ Wade, ${ }^{3} \mathrm{GA}$ Goldberg, ${ }^{3} \mathrm{D}$ Batra, ${ }^{3} \mathrm{P}$ Kadlubek. ${ }^{1}$ Arizona Rheumatology Center, Phoenix, USA; ${ }^{2}$ Amgen, Inc., Thousand Oaks, USA; ${ }^{3}$ Protocare Sciences, Inc., Santa Monica, USA

10.1136/annrheumdis-2001.1161

\section{Background}

Objectives To evaluate incidence of clinically significant infections in RA patients treated with various RA therapies.

Methods Retrospective analysis of linked medical and outpatient pharmacy claims from 10/98-9/99 was conducted using a large managed care database (Protocare Sciences). Patients age 35 and older, having at least 2 claims more than 20 days apart with an ICD-9CM diagnosis for RA were selected for analysis. RA therapies, including anti-inflammatory agents, steroids, DMARDS, and other systemic anti-arthritic agents were classified and clinically significant infections were identified. Comparisons of infection rates between various therapies were assessed using Incidence Density Ratios.

Results Most of the 2,443 RA patients (86\%) received drug therapy specific for RA during the study period. Overall, 1,207 patients $(49 \%)$ had at least one infection, 783 patients $(32 \%)$ had at least one upper Respiratory Infection (RI), and 716 patients (29\%) had at least one non-RI. A greater proportion of patients who received direct RA therapy experienced an upper RI compared to those patients who did not (32.8\% vs. $27.8 \%)$. Patients had a statistically higher occurrence of infections for pneumonia and bronchitis during use of potentially immunomodulating therapy (IMT). Subgroup analysis of patients receiving IMT by steroid exposure is presented Table 1 . Incidence Density Ratios (95\% CI):

\section{Abstract FRI0032 Table 1}

\begin{tabular}{llll}
\hline & Bronchitis & Pneumonia & All upper RI \\
\hline IMT vs. & 1.98 & 2.73 & 1.14 \\
Non-IMT & $(1.36,2.88)$ & $(1.29,5.77)$ & $(0.93,1.39)$ \\
IMT w Steroids vs. & 2.48 & 12.00 & 1.61 \\
IMT w/o Steroids & $(1.38,4.47)$ & $(1.63,88.09)$ & $(1.16,2.23)$ \\
\hline
\end{tabular}

Conclusion Infections were common in patients on RA therapies with nearly half of all patients experiencing at least one infection during the 12 months studied. Selection of therapy associated with infections should be considered in the overall management of patients with rheumatoid arthritis.

\section{FRI0033 ERYTHROPOIETIN-RECEPTOR-EXPRESSION IN FIBROBLAST-LIKE SYNOVIOCYTES}

U Kessler, S Woelfer, N Kukoc-Zivojnov, JP Kaltwasser, B Moeller. Rheumatologie, Universitätsklinikum Frankfurt Am Main, Frankfurt Am Main, Germany

\subsection{6/annrheumdis-2001.1162}

Background The anaemia of chronic disease in patients with rheumatoid arthritis (RA) can be corrected by treatment with recombinant human erythropoietin (rHu-Epo). In addition to an increase of haemoglobin concentration during therapy with $\mathrm{rHu}-$ Epo, a significant reduction of disease activity was observed in different RA-studies. Especially the decrease of the number of swollen and tender joints during rhu-Epo treatment suggests a direct anti-inflammatory effect of $\mathrm{rHu}$-Epo.

Objectives As the expression of the erythropoietin-receptor (Epo-R) was recently shown for different non-erythroid cells as for example endothelial and neuronal cells, we investigated the expression of Epo- $\mathrm{R}$ in fibroblast-like synoviocytes to gain a first experimental approach for the observed anti-inflammatory effect of rHu-Epo in RA.

Methods We cultivated fibroblast-like synoviocytes derived from synovial membranes $(\mathrm{n}=17)$ or synovial fluid $(\mathrm{n}=13)$ that were gained from patients with RA $(\mathrm{n}=22)$, osteoarthritis $(\mathrm{n}=$ 3 ) or spondylarthropathy $(n=5)$. Biopsy material has been minced and digested with collagenase, fluid derived cells have been directly cultured. Cells were passaged two to five times and characterised by FACS analysis. Expression of Epo-R was determined by nested RT-PCR. The chosen primers annealed at Exon III (forward primer 1 and 2), Exon VIII (backward primer 1) and Exon VII (backward primer 2). The obtained PCR-product was sequenced by automated fluorescent DNA sequencing.

Results The cultured cells morphologically represented fibroblast-like cells. It was shown by FACS analysis that they were CD14 and CD86 negative and CD54 and CD90-Thy-1 positive. RT-PCR products representing the human Epo-R could be demonstrated in fibroblast-like synoviocytes from biopsy and arthrocentesis from patients with RA, OA and SpA. The specifity of the PCR products could be proven by sequencing of the product of three different cell-lines. The obtained sequence was completely identical with that of the DNA data base for more than 350 bases (Exon IV to Exon VI).

Conclusion We could demonstrate for the first time the expression of Epo-R in fibroblast-like synoviocytes. This observation gives evidence that $\mathrm{rHu}$-Epo directly afflicts fibroblast-like synoviocytes (via Epo-R) and therefore provides a possible 
explanation for the anti-inflammatory effect of $\mathrm{rHu}$-Epo in patients with RA.

\section{FRI0034 DOES HEAVY CAFFEINE INGESTION AFFECT THE EFFICACY OF METHOTREXATE}

${ }^{1} \mathrm{CM}$ Silke, ${ }^{1} \mathrm{MS}$ Murphy, ${ }^{1} \mathrm{~S}$ Busteed, ${ }^{2} \mathrm{~TB}$ Murphy, ${ }^{3} \mathrm{M}$ Phelan, ${ }^{1} \mathrm{MG}$ Molloy. ${ }^{1}$ Department of Rheumatology, Cork University Hospital; ${ }^{2}$ Department of Statistics, Trinity College, Dublin, Ireland; ${ }^{3}$ Department of Rheumatology, South Infirmary Victoria Hospital, Cork

\subsection{6/annrheumdis-2001.1163}

Background In a proportion of patients methotrexate (MTX) has to be withdrawn because of lack of efficacy or side effects. MTX results indirectly in increased adenosine release. Adenosine, acting at the $\mathrm{A} 2$ receptor, mediates the anti-inflammatory effects of MTX. Caffeine is a non selective adenosine receptor antagonist and reverses the anti-inflammatory effects of MTX in the rat adjuvant arthritis model.

Objectives To see if there was any correlation between withdrawal of MTX due to treatment failure and caffeine ingestion.

Methods Over a 10 month period 91 sequential patients in 2 centres who had ever been on MTX were interviewed. They were classified as either minimal or regular coffee drinkers dependant on whether they drank more or less than 7 cups of coffee per week. Concomitant theophyline medication and tea and cola ingestion were also documented. Doses used varied from 5 to $15 \mathrm{mg}$ weekly (mean $=10.3 \pm 2.75$ ).

Results The proportion of people who have to discontinue MTX is higher in those who are regular coffee drinkers ( $\mathrm{P}$ value $=0.02$ ). In this group the reason for discontinuing was due to treatment failure in $80 \%$ of cases. $90 \%$ of those still on MTX and $74 \%$ of those who discontinued MTX were minimal coffee drinkers.

Conclusion Patients who are on MTX should decrease their caffeine intake as there is a statistically significant increase in treatment failure in those who drink coffee regularly. This may account for the reason that much higher doses of MTX are used in countries with a heavier caffeine consumption.

\section{FRI0035 RISK FACTORS FOR CLINICALLY IMPORTANT UPPER GI EVENTS: THE VIGOUR STUDY}

${ }^{1} \mathrm{C}$ Bombardier, ${ }^{2} \mathrm{~L}$ Laine, ${ }^{3} \mathrm{AS}$ Reicin, ${ }^{4} \mathrm{DR}$ Shapiro, ${ }^{3}$ RS Sperling. ${ }^{1}$ Institute for Work \& Health, Mt. Sinai Hospital, Toronto, Canada; ${ }^{2}$ GI Division, USCSM, Los Angeles; ${ }^{3}$ Clin. Res; ${ }^{4}$ Biostat., Merck \& Co., Rahway, USA

10.1136/annrheumdis-2001.1164

Background The VIGOUR (VIOXX GI Outcomes Research) study was a prospective, randomised, double-blind comparison of rofecoxib (a COX-2 inhibitor) vs. naproxen (a dual COX-1/ COX-2 inhibitor) in $>8000$ patients with rheumatoid arthritis (RA). The study showed that rofecoxib was associated with significantly fewer clinically important upper gastrointestinal (GI) events (perforation, obstruction, bleeding, symptomatic gastric and duodenal ulcers) than naproxen.

Objectives To assess whether the risk reduction in clinically important upper GI events seen with rofecoxib was similar in "high risk" and "low risk" sub-populations; and, to predict the risk of these events based on baseline characteristics.

Methods In the VIGOUR trial, 8076 RA patients expected to require NSAIDs for $>1 \mathrm{yr}$ were randomly assigned rofecoxib $50 \mathrm{mg}$ qd or naproxen $500 \mathrm{mg}$ bid for minimum of 6 -month follow-up. Patients were classified as "low risk" or "high risk" for clinically important upper GI events based on recognised risk factors - age, steroid use, previous history of clinical GI events, and $\mathrm{H}$. pylori sero-status. Relative risk analyses were conducted in both low- and high-risk subgroups. A multifactorial model to predict clinically important upper GI events was developed. Multiple steps in the analysis included: 1 . Covariates were examined in a univariate Cox model; 2 . Factors that trended $(\mathrm{p}<$ 0.20 ) plus treatment were put into Cox model and backwards stepwise regression chose significant $(\mathrm{p}=0.05)$ predictors; and, 3. Interactions between each covariate with treatment were tested one at a time in Cox models.

Results The \% risk reduction (rofecoxib relative to naproxen) of clinically important upper GI events was $88 \%$ in the low-risk subgroup, $51 \%$ in the high- risk subgroup and 54\% in the overall population.

\begin{tabular}{lll} 
Abstract FRI0035 Table 1 & & \\
\hline & Relative risk $(95 \% \mathrm{Cl})$ & p-value \\
\hline $65-74$ vs & $2.37(1.70,3.30)$ & $<0.001$ \\
Uncomplicated vs No Hx of PUBs & $3.08(1.98,4.77)$ & $<0.001$ \\
Complicated vs No Hx of PUBs & $3.73(2.25,6.17)$ & $<0.001$ \\
ARA Class IV vs I/II/III & $2.27(1.10,4.69)$ & 0.027 \\
Prior Hx GI symptoms vs none & $1.81(1.28,2.56)$ & $<0.001$ \\
Prior H2 blocker use vs none & $1.62(1.09,2.43)$ & 0.018 \\
Prior steroid use vs none & $1.59(1.15,2.18)$ & 0.005 \\
Prior NSAID use vs none & $0.57(0.40,0.79)$ & $<0.001$ \\
\hline
\end{tabular}

Risk Factors for Clinically Important Upper GI Events based on Multifactorial Model.

Conclusion (1) The relative risk reduction of GI events in the rofecoxib group was maintained in both the high and low risk subgroups. (2) Multivariate analyses found the risk factors significantly associated with GI events to include age, prior history or clinical GI events (complicated and uncomplicated), disease severity, duration of disease, prior history of GI symptoms, prior use of low dose $\mathrm{H} 2$ blockers, steroids, and NSAIDs.

\section{FRI0036 POPULATION PHARMACOKINETICS (PK) OF ANAKINRA IN SUBJECTS WITH RHEUMATOID ARTHRITIS (RA)}

${ }^{1} \mathrm{~B}$ Yang, ${ }^{1} \mathrm{~J}$ Frazier, ${ }^{2} \mathrm{D}$ McCabe, ${ }^{1} \mathrm{JD}$ Young. 'Pharmacokinetics and Drug Metabolism; ${ }^{2}$ Rheumatology Professional Services, Amgen, Thousand Oaks, USA

10.1136/annrheumdis-2001.1165

Background Anakinra is a recombinant interleukin-1 receptor antagonist that reduces signs and symptoms and slows joint destruction in RA patients in clinical trials. Population PK analysis was conducted on data from RA patients treated with anakinra.

Objectives The objective was to investigate the effect of covariates such as creatinine clearance (CLcr), body weight (WT), age, and sex, on anakinra PK.

Methods Subjects $(n=341)$ received daily SC injections of anakinra at 30,75 , or $150 \mathrm{mg}$ for 6 months; one plasma sample for anakinra measurement was collected from each subject at baseline, and at weeks 1, 4, 12, 20, and 24 before anakinra administration for that day. Plasma samples were analysed for anakinra levels by an ELISA method. Plasma anakinra data were analysed by nonlinear mixed-effects modelling using NONMEM. 